\title{
EL ARTE FRENTE A LA TECNOLOGIA: EL EXTRAÑO CASO DE LA MÚSICA POPULAR *
}

\section{Simon Frith}

A principios de 1936, Cecil Graves, director de programación de la $\mathrm{BBC}$, dio instrucciones al jefe de variedades, Eric Maschwitz, y al de programas musicales, Roger Eckersly, para que excluyeran de sus emisiones la canción melódica, ${ }^{* *}$ "esa manera particularmente odiosa de cantar». ${ }^{1}$ En las memorias de su vida en la BBC, Eckersly comenta sobre los cantantes melódicos:

«Parece ser, por mi experiencia, que suscitan, en ciertos corazones, más pasiones diabólicas que cualquier otra cosa. Desearía señalar que no todos los que cantan con grupos musicales son cantantes melódicos. Estos últimos tienen un arte propio. No puedo decir que me guste, pero admiro la maestría con que el vocalista parece detenerse, durante una fracción de segundo, un poco más arriba o más abajo de la nota que pretende emitir» (Eckersly, 1946, p. 144).

La canción melódica es un estilo de cantar que se hizo posible gracias a la evolución del micrófono eléctrico (los vocalistas podían ser escuchados

* Este artículo fue publicado originalmente en la revista Media, Culture and Society (SAGE, Londres, Beverly Hills and Nueva Delhi; vol. 8, núm. 3 (1986), pp. 263-279). Traductor: Carlos Peñalver.

** «Crooning» significa: "canción melódica», «canturreo» o «tarareo», en el sentido de que se necesitan pocas cualidades para ello. (N. del T.)

1. Quiero dar las gracias a Paddy Scannell por los detalles de esta disputa. 
cantando en voz baja). El micrófono fue el origen de un nuevo tipo de cantantes pop masculinos (Rudy Valee, Bing Crosby, Al Bowlly), a los que la $\mathrm{BBC}$ consideraba «sensibleros» y «afeminados» ( $\mathrm{La}$ interrelación de la canción melódica con la decadencia sexual iba a ponerse de manifiesto muchos años después con Pennies from Heaven de Dennis Potter.) De entra$\mathrm{da}$, los jefes de programación de la $\mathrm{BBC}$ se encontraban con un problema: definir la canción melódica. Después, tenían que distinguir entre las «buenas» y las «malas». Incluso después de la guerra, la Ted Heath Band no pudo estar en antena debido a que su cantante, Lita Roza, fue considerada melódica y, por lo tanto, «sensiblera» (Heath, 1957, pp. 94-95).

Veinte años más tarde, en 1966, Bob Dylan realizó una gira por Gran Bretaña con su nueva banda eléctrica. El concierto del Albert Hall fue boicoteado. Todavía pueden escucharse las palmadas lentas y acompasadas entre canción y canción, los insultos dirigidos al escenario y las discusiones a voz en grito entre los asistentes. Al finalizar «Ballad of a Thin Man», se escucha claramente una voz metálica: «iJudas!», «No te creo», murmura Dylan al comenzar los acordes de «Like a Rolling Stone».

Quince años después, el cambio tecnológico va acelerando su paso. Recibí la llamada de una joven banda de Coventry, inmersa en la batalla local de los grupos que quieren ser apadrinados por el Sindicato de Músi$\cos (\mathrm{SM})$ (eslogan: ¡Mantén la Música Viva!). Su entrada había sido denegada (utilizan caja de ritmos). ¿Fue por razón de la política del sindicato? La respuesta es sí (aunque, desde luego, dicha política está siempre abierta al debate y al cambio). En palabras de Brian Blein, encargado de publicidad y promoción del SM:

«Primeramente debo decir que el sindicato pretende limitar el uso de sintetizadores allá donde su utilización prive a las orquestas de su trabajo. Hasta ahora, especialmente en las contrataciones para los medios de comunicación y en las giras de cantantes del calibre de Andy Williams u otros, hemos tenido un cierto éxito.

"Creo, sin embargo, que acredita al sindicato el hecho de que entendamos la diferencia esencial entre el uso del sintetizador cuando quita trabajo a los músicos "convencionales", y su empleo por parte de bandas o grupos autónomos en los que normalmente no se plantea la posibilidad de utilizar los servicios de otro músico. Adentrándonos en este punto de vista admitidamente pragmático, vemos que tan sólo continuamos con el problema que siempre han suscitado los instrumentos de teclado, por el que existe la actual reglamentación. El piano acústico podría también ser considerado, en principio, como desplazante de un cierto número de músicos, 
lo que desde luego ha sido un hecho desde el nacimiento del órgano Hammond.

»Es inútil buscar un punto de vista de total consistencia, pero quiero decir que veo una gran diferencia entre el sintetizador utilizado por una banda o grupo, el cual requiere al menos un músico que lo toque, y la máquina que directamente sustituye al músico.» ${ }^{2}$

\section{POP Y AUTENTICIDAD}

Estos disparatados ejemplos de controversias originadas por las técnicas cambiantes de la creción musical sugieren tres reflexiones. En primer lugar, la tecnología es opuesta a la naturaleza. La esencia del caso de la "canción melódica» en la $\mathrm{BBC}$ es que era «antinatural». Los cantantes «legítimos» de ópera o music-hall llegaban a sus audiencias con el sólo poder de sus voces. El sonido de los cantantes melódicos, por el contrario, era artificial. Los micrófonos permitían que los sonidos íntimos alcanzaran una presencia pseudopública, y, para los críticos de los cantantes melódicos, la deshonestidad técnica conlleva deshonestidad emocional. De ahí, términos como «sensiblero». Los cantantes masculinos eran poco naturales: en particular se cuestionaba su sexualidad y eran acusados de «emascular» la música. Hasta Eckersly contrastó la canción melódica con la «auténtica» forma de cantar.

En segundo lugar, la tecnología es opuesta a la comunidad. Esta argumentación, frecuente en la escena folk a principios de los sesenta, propugna que la amplificación electrónica aparta a los intérpretes de sus audiencias. La estructura democrática de la comunidad folk no fue capaz de sobrevivir a una situación en la que los cantantes iban a monopolizar el nuevo medio de comunicación, la corriente eléctrica. «Haciéndose eléctrico», Bob Dylan abrazó todas aquellas cualidades de la cultura de masas que el movimiento folk había rechazado: estrellato, comercio y manipulación.

En tercer lugar, la tecnología es opuesta al arte. La objeción del SM al uso de cajas de ritmos es, en parte, una postura convencional del mismo en defensa de las oportunidades de trabajo de sus miembros, pero refleja también la creencia de que el batería es un músico en un sentido en que no lo es el programador de la caja de ritmos. Uno de los efectos del cambio tecnológico es que complica la distinción entre «músico» e «ingeniero de sonido», lo que implica que los músicos son artistas creativos mientras

2. Carta de Brian Blain, del 12 de marzo de 1981. 
que los ingenieros no lo son. No se trata en este caso de la difícil cuestión de la creatividad misma, sino más bien de la idea de autoexpresión. La prensa pop de los setenta planteó, repetidamente, que la producción de ruidos mediante sintetizadores no dejaba lugar al «toque» o «sentimiento» individuales. Gary Numan podía indicar a los lectores de la página de asesoramiento, a los músicos del Melody Maker cómo reproducir su sonido, mientras que no podían hacer lo mismo Jeff Beck o Keith Emerson. Éstos podrían describir sus técnicas, pero no el resultado final. Todo lo que Numan tenía que hacer era transcribir la posición de los distintos interruptores. En este contexto, los sintetizadores se consideraban «desalmados». Su utilización más señalada fue para la banda sonora de La Naranja Mecánica. La novena sinfonía de Beethoven, sintetizada por Walter Carlos, era el símbolo musical de la película (el deshumanizador empleo del arte como terapia de comportamiento). La marcha de La Naranja Mecánica se utilizó más tarde, con efectiva ironía, como música de apertura para el espectáculo escénico de David Bowie, en 1972.

Lo que se pone juego en todo este debate es la autenticidad o veracidad de la música. Esto implica que, de alguna manera, la tecnología es falsa o adulterante. Los orígenes de esta discusión datan, sin duda, del criticismo hacia la cultura de masas de los años veinte y treinta, pero lo que resulta interesante es la resonancia continua de la idea de autenticidad dentro de la propia ideología de la cultura de masas. Las controversias básicas de la historia del rock, por ejemplo, se han resuelto (incluso vendido) con forma de nuevas, auténticas estrellas que sustituyen a las antiguas, no auténticas. En su primer LP con la RCA, Elvis Presley aparece tocando una guitarra acústica, y la propaganda de la contracubierta comienza:

«Elvis Presley irrumpió en el gran mundo del espectáculo prácticamente de la noche a la mañana. Nacido en Tupelo, Mississipi, Elvis comenzó a cantar para amigos y reuniones folk cuando apenas contaba cinco años. Toda su preparación ha sido autodidacta, a base de trabajar duro. Ya a una temprana edad, y sin dinero suficiente para comprar una guitarra, practicaba para su futuro estrellato rasgueando el palo de una escoba. Pronto se pudo proporcionar un instrumento de 2,98 dólares y comenzó a sacar canciones y a cantarlas por las esquinas.»

A mediados de los sesenta, las que ahora son rutinas convencionales del pop adolescente fueron desafiadas, alternativamente, por la «auténtica movida del ritbm and blues blanco». En palabras de su biografía oficial de 1964: 
«Los Stones tomaron el Rytbm'n'Blues, pelearon con él, aprendieron a sentirlo. Una vez que se habían hecho a la idea de abrazarse a él, aun pasándolo muy mal, nada podía apearles de su decisión. Habían tomado la determinación de expresarse libremente, a través de su música.

"Decidieron unánimemente que no iban a hacer concesiones a las demandas de comercialización que tanto, y tan abiertamente, rechazaban» (The Rolling Stones, 1964, p. 13).

Una docena de años más tarde, los músicos punk hicieron tambalearse al establisbment del rock con una actitud similar, si no más apocalíptica. Según palabras de Caroline Coon en el Melody Maker de Julio de 1976:

«Existe un sentimiento creciente, casi desesperado, de que la música rock debe ser llevada de nuevo a sus raíces, cogiéndola por su envanecido cogote y pegándole una buena sacudida.

»No es casualidad que la misma semana en que los Stones tocaban en Earls Court los Sex Pistols estuvieran tocando ante su siempre creciente auditorio en el $100 \mathrm{Club}$. Los Pistols son la personificación de la floreciente escena del punk-rock británico, una positiva reacción ante el complejo instrumental, la sofisticación tecnológica y la exigua alienación que han formado una barrera entre los seguidores y las estrellas.

„El punk-rock suena básico y natural. Esto es lo que pretende» (Coon, 1976, p. 14).

Cada uno de estos momentos de la historia fundía juicios estéticos y morales: rock and roll, rbythm and blues y punk, cada uno en su momento, fueron experimentados como más auténticos que las formas pop que desplazaron. Y en cada uno de los casos, la autenticidad se describió como una reacción explícita contra la tecnología, como un retorno a las «taíces» del bien-hacer de la música, al encanto vivo de las líneas de guitarra/batería/voz. El eje continuo de la ideología rock es que los sonidos naturales son más auténticos que los cocinados.

Es una creencia paradójica para un medio de sofisticada tecnología, y descansa en un modelo anticuado de comunicación directa: $A$ mueve a $B$, y cuanta menos tecnología haya entre ambos más honesta será su relación y menores las posibilidades de manipulación y falsedad. Es un modelo que descansa nuevamente en las posturas estéticas de la familia. Los fans del rock han heredado del Romanticismo la creencia de que escuchar la música de alguien significa conocerle, entrar en su alma y en su sensibilidad. De la tradición folk han adoptado el argumento de que los músicos pueden representarles, articulando las necesidades y experiencias inmediatas de un 
grupo, culto o comunidad. Además, se considera que la buena música es, tanto por arraigo como por criterio, honesta y sincera. La música mala es falsa, y los cambios tecnológicos aumentan las oportunidades de falseamiento. Tomemos esta típica historia de un periódico de 1985:

«Cuando esta noche Frankie Goes to Hollywood abra sus puertas, a medio camino en su gira británica, se encontrará con un problema técnico: cómo reproducir, en una actuación de 90 minutos, el sonido artificial de sus éxitos, que tantos meses de estudio de grabación le ha costado producir utilizando sofisticado bardware, del más caro que se puede comprar.

"Hoy día, muchos grupos tienen este problema. Algunos ni siquiera tratan de resolverlo. Dead or Alive (Vivos o Muertos), otro grupo de Liverpool, cuyo You Spin Me Round está actualmente en la cumbre de las listas inglesas, canceló su aparición en el programa de rock del canal 4 de televisión, The Tube, hace dos semanas. Rechazó aparecer sin cintas previamente grabadas. Su uso estaba en contra de la política "sólo en vivo" del programa.

"Este penoso relato sería sólo una nota a pie de página en la larga y peculiar historia del fraude en la música pop. Hay un número de grupos (reduciéndose en los últimos 20 años) que llenaban por su sex appeal y que tocaban bastante poco en las grabaciones de sus propios "éxitos". Otros eran fabricados después del evento, tan sólo poniendo una cara vendible al honesto aunque anónimo repertorio de músicos de sesión y productores» (Brown, 1985).

Resulta intrigante, desde luego, la distinción entre «fraude» en lo que respecta a tecnología y «fraude» en cuanto a manipulación comercial. Dos tipos de falta de sinceridad que se confunden, y que nos llevan a los anónimos músicos de sesión que pueden calificar su trabajo de «honesto». El barullo de términos críticos que aparecen en este tipo de controversia, la implicación de que no podemos «creer» lo que estamos oyendo, reflejan la confluencia de tres problemas que la tecnología plantea en estos momentos al concepto rockero de autenticidad.

Primero: hay un problema de aureola en el complejo proceso de producción artística: ¿cuál o, mejor dicho, quién es la fuente de creación de un tema pop? La historia del rock and roll se mueve en una serie de suposiciones tan complicadas como la historia del cine (y el rock tiene su propia versión de la teoría del autor). Siempre existe la necesidad de que alguien sea el autor de un sonido, el artista, pero el significado artístico relativo de escritores/músicos/cantantes/productores/ingenieros/arreglis- 
tas es cambiante. Actualmente es posible para un publicista ser acreditado como autor real de un disco - piénsese en la función de Paul Morley en la venta de Frankie Goes to Hollywood. Frankie, el fenómeno pop de 1984, obtuvo su éxito con una alegre celebración de su propio artificio. La producción, por parte de Trevor Horn, convirtió a un laborioso grupo de Liverpool en una sensación tecno-flasb-disco-envolvente. Sus vídeos de «Relax» y «Two Tribes» presentaban una versión camp de la masculinidad. La superproducción de Frankie se distribuyó entre algodones de copia publicitaria. El envoltorio la presentaba como arte, y de esta manera el teórico pop Paul Morley, que escribió la prosa para Frankie y su etiqueta ZTT, fue reconocido como auténtico autor. Incluso llegó a aparecer en escena, en el show ZTT, leyendo su copia sobre una cinta de fondo grabada como una maravilla del ruido.

Segundo: los cambios tecnológicos aumentan el problema del poder y la manipulación. ¿Cómo se relaciona la propiedad de los medios técnicos de producción con el control de lo que se produce? ¿El desarrollo técnico amenaza o consolida este control?

Tercero: se considera que la tecnología mina los placeres de la composición musical (y de la observación de la misma). Una importante fibra del sentido común del rock es que tocar un instrumento es un ejercicio físico que visiblemente envuelve al cuerpo, y es, por encima de todo, una cuestión de esfuerzo. Esto se refleja en el rutinario contraste entre actuación en «vivo» y actividad «muerta» de estudio; incluso ahora, las creencias básicas del rock en cuanto a que energía y comunidad sólo pueden celebrarse en concierto: de aquí la importancia de Bruce Springsteen. El guitarrista se convirtió en el símbolo del rock porque él (la masculinidad es parte necesaria en el argumento) se comunica físicamente desde el escenario aún más obviamente que el cantante. La ligazón entre sonido y gesto se ha hecho tan familiar que las audiencias han llegado a inventar la «guitarra de aire», que no es sino una manera de compartir las emociones físicas del guitarrista sin necesidad alguna de instrumento.

Una de las razones por las que sintetizadores, cajas de ritmos, magnetófonos y otras máquinas se consideran instrumentos «antinaturales» en directo es, simplemente, porque tocarlos no conlleva un visible esfuerzo. Programar una unidad de sampling computerizada concierne a la mente y no al cuerpo, y por lo tanto no es un evento para espectadores. (Los auditorios musicales, acostumbrados a la acción de orquestas y directores, se sienten igualmente insultados por los músicos de computadora.) El argumento explícito radica en que las actuaciones en vivo dan pie a la espontaneidad, a la respuesta directa del que actúa hacia el público. Los instrumentos programados no tienen esta posibilidad. Pero lo que realmente 
importa no es si una actuación es espontánea o no, sino más bien si parece serlo (los artistas más cotizados en vivo suelen tener sus shows rígidamente controlados - vayan a ver a James Brown durante varias noches seguidas y verán exactamente las mismas «improvisaciones»). El empleo de ayudas «artificiales» por parte de las bandas de rock está, consecuentemente, escondido (por ejemplo, el uso de cintas pregrabadas es ahora rutinario) o disimulado (los fabricantes de instrumentos electrónicos se están especializando en la producción de aparatos que pueden tocarse como si fueran teclados o instrumentos de percusión normales, no es necesario el diseño de una máquina de ritmos semejante a un Syndrum o a un Kit Simmons, como algo para ser golpeado). Si se descubre el engaño, las audiencias se sienten sin duda ultrajadas. En cierta ocasión vi a Vince Clarke de Yazoo pretender tocar su Fairlight * (todo lo que estaba haciendo era cargar y descargar los floppy discs). Cuando finalmente se cansó y se fue caminando, mientras la música seguía sonando, fue abucheado incluso con más fuerza de lo que lo fue Dylan en el Albert Hall.

\section{EN ELOGIO DE LA TECNOLOGIA}

Para los fans de Yazoo, al igual que para los de Dylan, un par de generaciones $p o p$ antes, las nuevas tecnologías significan nuevos medios de control de masas. La línea directa entre el artista y su público fue fatalmente interrumpida. Ésta es una postura conocida en el rock, como he mostrado, pero, de hecho, es una inversión de la realidad. Una historia más desapasionada del pop del siglo veinte revela dos tesis contrarias.

\section{El desarrollo tecnológico ba becho posible el concepto de autenticidad en el rock}

Puedo ilustrar este concepto haciendo referencia a las tres invenciones fundamentales del pop. En primer lugar, la grabación magnética. Desde sus orígenes al cambiar el siglo, posibilitó la reproducción exacta de aspectos de la actuación (espontaneidad, improvisación, etc.) previamente irreproducibles, lo que permitió que la música afroamericana sustituyera al folk y a la música culta europea como eje de la cultura popular occidental. Esto afectó no sólo al tipo de música que la gente escuchaba (cada vez

* Instrumento para sampling computerizado. (N. del T.) 
más después de la Primera Guerra Mundial), sino también a cómo lo hacían; a cómo registraban el sentido emọcional de los sonidos, por un lado; y a la forma musical de sus propias emociones, por el otro. La grabación permitió el impacto físico de un actor invisible, posibilitando el acceso al sentir de los cantantes sin necesidad de que estuvieran codificados sus sentimientos mediante una notación escrita.

Una de las consecuencias inmediatas fue que las estrellas de la canción comenzaron a reemplazar a los compositores como «autores» de la música popular (también es un hecho en la música clásica, Caruso fue la primera estrella de la grabación internacional), pero lo más importante es que la grabación proporcionó un medio público de comunicación emocionalmente compleja a personas que de otra forma estarían inarticuladas socialmente: intérprete y audiencia. Los cantantes de blues y de billbilly de los años veinte y treinta estaban tan afectados y limitados como los juglares románticos de la tradición medio clasista europea, pero sus normas podían comprenderse y aprenderse sin necesidad de la educación y enseñanza cultural necesarias para apreciar la forma en que la música clásica transmite su significado. Las profundas manifestaciones de orgullo, espanto y desafío que tiene un blues de Robert Johnson, los sutiles giros de deseo y de dolor de una canción de Billie Holiday se pueden escuchar con la misma intensidad y autenticidad por parte de oyentes distantes geográficamente, socialmente y en cuanto a sus raíces culturales. Todavía puedo recordar el regocijo instantáneo que me produjo Long Tall Sally de Little Richard, cuando la escuché por primera vez, con unos diez años, mientras crecía en una pequeña ciudad de Yorkshire, sin tener la menor idea de quién o qué era Little Richard. Esa conversión a la música negra, similar a la experiencia de los niños de clase media de una ciudad pequeña, antes de la guerra, al escuchar a Louis Armstrong por primera vez, se estaba repitiendo en los jóvenes de toda Europa a resultas del rock and roll, y no puede explicarse satisfactoriamente en términos de imperialismo comercial de la cultura.

La segunda invención importante, el micrófono eléctrico, ya ha sido comentada anteriormente, cuando hablamos de los cantantes melódicos, pero su efecto general fue el aumentar las posibilidades de expresar públicamente los sentimientos privados en todos los géneros del pop. El micrófono tuvo la misma función que el primer plano en la historia del cine: hizo reconocibles a las estrellas, alterando los convencionalismos de la personalidad, con nuevos modos de sonar sexy entre los cantantes, dando al hombre un nuevo papel prominente en las big bands, y moviendo el foco de atención de la canción al cantante. El primer cantante pop que se convirtió en ídolo indiscutible, Frank Sinatra, era perfectamente consciente 
de la importancia de la amplificación en su atractivo. Como escribe John Rockwell:

«Cuando era un joven cantante, perfeccionó a conciencia su manejo del micrófono. "Muchos cantantes nunca aprendieron a usarlo -escribiría más tarde- Jamás entendieron, y siguen sin entender, que el micrófono es su instrumento." Un micrófono debe ser manejado con moderación, acercándolo y alejándolo de la boca para suprimir excesivos silbidos y ruidosas aspiraciones de aire. Pero la identificación de Sinatra con el micro fue más allá del mero nivel técnico. Conocía mejor que casi ningún otro la afirmación de Henry Pleasants: que el mictófono cambia profundamente la manera de cantar de los vocalistas modernos. Fue su maestría con el instrumento, la manera en que se apoyaba en su existencia para ayudar a conformar su producción vocal y su estilo de cantar, lo que más hizo en favor de Sinatra para convertirlo en una preeminente figura popular de nuestro tiempo» (Rockwell, 1984, pp. 51-52).

Sinatra permanecería sensible a los desarrollos de la tecnología. En los años cincuenta fue pionero del uso del LP, para crear climas y atmósferas que sería imposible plasmar en un single de tres minutos. Desde esta perspectiva propia, la tecnología era una herramienta a utilizar, de la que, a su vez, era fácil abusar. Sinatra, en una famosa declaración acorde con la del crítico de jazz del New York Times, John S. Wilson, despachó a Elvis Presley y al rock and roll al decir que «la capacidad para cantar es una de las cualidades menos importantes para tener éxito» en el nuevo pop:

«Las técnicas de grabación se han hecho tan ingeniosas que casi cualquiera puede parecer un cantante. Una voz plana y débil puede ser arropada mediante la enfatización de las bajas frecuencias, pasándola posteriormente por una cámara de eco. Una ligera aceleración de la cinta puede dar brillo y vivacidad a un cantante monótono y limpiar los fallos de una voz cansada. Las notas equivocadas se pueden borrar de la cinta y ser sustituidas por nuevas» (Levy, 1960, p. 111).

De hecho, Elvis Presley ni corrompió ni transformó la tradición pop, fue la estrella culminante de la tecnología de la grabación y amplificación eléctricas. Para las fans de Presley, él era mucho más sexy, bonestamente bablando y en el presente, que Frank Sinatra.

La tercera invención importante, la cinta magnética, comenzó a utilizarse en las compañías de grabación en los años cincuenta, e hizo eventualmente posible el cortado/repicado/doblado/mezcla multicanal de sonidos, 
de manera que la música de estudio se convirtió en algo enteramente artificial. Lo que para John Wilson era una forma de fraude, para los músicos de rock de los años sesenta se convirtió en fuente de creatividad. La mayor parte de los productos del desarrollo tecnológico (tocadiscos, alta fidelidad, cinta magnética, sonido estereofónico, grabación digital, compactos, etc....) han sido impulsados por las clásicas casas de discos, ya que los productores e ingenieros de sonido han tratado de encontrar formas de capturar la dinámica auditiva de la música orquestal viva. En el pop, sin embargo, pronto se utilizaron estas técnicas en sentido contrario: los estudios se convirtieron en el lugar para hacer música imposible de reproducir en vivo, en lugar de recrear la experiencia del concierto. A finales de los años sesenta el estudio era, en sí mismo, el instrumento más importante del rock. El LP Sergeant Pepper's..., de los Beatles, simbolizó el momento en que los músicos de rock comenzaron a reivindicar la autoría de complicados trabajos artísticos.

La progresión del rock planteó un problema a las ideas de autenticidad recibidas: los ideales rock and roll de espontaneidad, energía y esfuerzo se enfrentaban al nuevo énfasis, depositado en la sensibilidad, en el cuidado y en el control. El rock de los años setenta ofreció dos soluciones. Por un lado, se combinaron esfuerzo y control en las espectaculares exhibiciones tecnológicas de los grupos de rock-arte como Pink Floyd o de los rockeros de estadio como Led Zeppelin. Por otro lado, los cantautores como Paul Simon, Joni Mitchell, e incluso John Lennon, utilizaron aparatos de estudio y collages sonoros para abrirse más al público, haciendo de la música un tema de sensibilidad individual que no podía encajar en el local crudo y colectivo de la sala de conciertos. El punk se iba a revelar contra el exceso de demostraciones tanto tecnológicas como artísticas, pero el gran moralismo del punk reveló lo enmarañada que estaba la estética del rock hasta esos momentos, a causa de las ideas de honestidad y deshonestidad.

El punk tan sólo interrumpió momentáneamente el desarrollo de la tecnología pop (un desarrollo que para los años ochenta ya había conducido al colapso total de las distinciones creativas entre músicos, productores e ingenieros) pero ilustra mi segunda tesis histórica.

\section{El cambio tecnológico ba sido una fuente de resistencia frente al control corporativo de la música popular}

Este planteamiento vuelve a rebatir la historia ortodoxa del pop. Por lo tanto, en primer lugar, necesito clarificar mi postura: si observamos las 
invenciones de la industria de la música a través de su historia, en cuanto a la producción y al consumo, veremos que las que tienen aceptación y aparecen con éxito en el mercado son aquellas que conducen, al menos a corto plazo, a la descentralización de la composición, interpretación y escucha de la música. Como ejemplo reciente, vemos que los videocassettes se han popularizado, mientras que no ha ocurrido lo mismo con los videodiscos. $\mathrm{El}$ argumento típico se basa en que el cambio tecnológico se ha inspirado en el control capitalista del mercado, al que también hace posible. Pero, por lo general, la tecnología de la grabación no ha funcionado así. La industria de la música es esencialmente conservadora, y utiliza los nuevos instrumentos para hacer cosas viejas con mayor eficacia o para hacerlas más baratas, en lugar de hacer cosas nuevas. Esto es obvio, por ejemplo, en el desarrollo del equipo musical. Algunos instrumentos se han inventado en respuesta a las demandas de los músicos (el bajo eléctrico, los amplis Marshall). Pero los músicos han encontrado rápidamente usos inesperados para ellos, por lo que muchas herramientas electrónicas se han producido sin tener una idea exacta de cuál iba a ser su uso, excepto, claro está, las que sustituyen a los antiguos instrumentos. De ahí la importancia de los músicos para los fabricantes de sintetizadores. Ellos tocarán sus instrumentos y propiciarán su venta al demostrar sus nuevas posibilidades.

Es porque los músicos (y consumidores) han podido utilizar las máquinas para sus propios fines, por lo que la mecanización de la música popular no ha sido una simple historia de toma de poder capitalista (o de control del Estado). Esto ha sido cierto a lo largo de toda la historia del pop.

La amplificación eléctrica, por ejemplo, y en particular el desarrollo de la guitarra eléctrica en los años treinta, dio a los músicos americanos la posibilidad de viajar y actuar ante grandes audiencias sin el tremendo gasto de las big bands. Mientras tanto, el desarrollo paralelo de las técnicas de grabación arrebató el poder a los productores de vaudeville y a los propietarios de locales de baile, quienes decidían hasta entonces quién podía escuchar a quién. Los nuevos guardabarreras de la industria, disc-jockeys de radio y relaciones públicas de las compañías discográficas, tenían mucho menos control sobre quién podía hacer música para vivir. Esto fue especialmente importante para la música negra y para sus músicos, y para que la música negra estuviera abierta al público blanco. El teclado «sintético» original, el órgano Hammond, se comenzó a vender como un instrumento doméstico ( $i s o n i d o s$ para poder disfrutar en casa!). Es discutible que el proceso creativo del rock, a partir de Los Beatles, se haya inspirado en la lucha de los músicos por conseguir por sí mismos, con el instrumental que hayan podido reunir, sonidos que se originaron en el estudio de grabación. 
Más que haber estado oprimidos por la desigual distribución del poder tecnológico, los músicos se han vuelto inventivos con él. Por lo tanto, la invención en el rock es inseparable tanto del empleo de la tecnología como de los intentos de los músicos por controlar sus propios sonidos.

$\mathrm{El}$ ejemplo más sorprendente fue el punk. Su ideología puede haber sido antitecnológica, pero la invasión a finales de los años setenta de discos caseros y etiquetas independientes dependía, de hecho, del descenso de los precios en los equipos de grabación de buena calidad, y de la disponibilidad de teclados electrónicos baratos aunque sofisticados. El movimiento punk incluía músicos electrónicos como Thomas Leer y Robert Rental, Cabaret Voltaire y The Human League. La etiqueta independiente de más éxito, The Mute, ha funcionado, casi exclusivamente, con repertorio electro-pop.

En la última década, todos los tipos de música de vanguardia se han hecho bajo la influencia del punk. A largo plazo, resultó que el reto punk a las formas establecidas de estrellato y autoridad fue más claro en cuanto a la música que sociológicamente. Los punk no sustituyeron el orden establecido por el pop sobre estrellas y seguidores, pero los músicos postpunk han desafiado la idea del producto terminado. En los años ochenta, ha sido la forma comercial y no el estatus comercial lo que se ha puesto en entredicho. Estrellas, discos y canciones enlatadas han sido objeto de mayor juego y manipulación.

Parte de ello ha venido de manos de los propios consumidores. La grabación doméstica ha dado nuevas posibilidades a los fans para tener control sobre sus sonidos. Puede recopilar elepés y transmisiones radiofónicas, y utilizar walkmans para transportar consigo sus panorámicas sonoras. La industria discográfica ha considerado a la grabación doméstica como principal causante de todos sus problemas. En el transfondo de las campañas que piden gravar con impuestos el precio de las cintas en blan$\mathrm{co}$, yace la suposición de que se utilizan para adquirir música ilegalmente, sin pagar por ella, sin dar ni siquiera a los músicos su recompensa por hacerla. Desde esta perspectiva, cada cinta en blanco vendida significa un disco sin vender.

Merece la pena tener en cuenta una serie de puntos que conciernen a este tema. En primer lugar, su base es una evidencia errónea. El efecto que produce la grabación casera en el mercado se deduce, en principio, de las cifras resultantes de la venta de discos, en lugar de hacerse llevando a cabo una investigación de las auténticas motivaciones del consumidor. Existe una evidencia desigual en este sentido (investigaciones llevadas a cabo por la Warners en los EE.UU., y por el Partido Comunista en Italia) que muestra, sin que haya motivo para sorpresa, que la grabación domés- 
tica la realizan personas que tienen una determinada relación con la música. La producen las personas que compran mayor número de discos. El efecto de sustitución (cinta comprada equivale a disco no vendido) no tiene sentido si está relacionado con la gente que gasta tanto dinero en música como puede. Resalta, sin embargo, el significado cambiante que ha tenido la música en relación con el tiempo libre. La compra de discos está siendo sustituida por otro tipo de actividades que no son la compra de cintas. La música está teniendo un uso diferente, con formas igualmente diferentes a la vez que más flexibles. (Warner Communications, 1982, 1985.)

También es interesante observar que los temores a este supuesto surgieron posteriormente a su aparición. Un ejemplo más de la ignorancia de las multinacionales sobre las consecuencias de sus propios inventos. Repitiendo lo que anteriormente expuse, las compañías discográficas son cortas de miras. Investigación y Desarrollo significan formas de sacar más dinero a la gente haciendo lo que siempre han hecho. Nadie pudo vaticinar el éxito del VTR (la Thorn-EMI decidió no invertir en su desarrollo inicial), porque las compañías normalmente confunden las modas pasajeras con las costumbres habituales (de ahí la macroinversión ciega de la Warners en los juegos Atari para computadoras). Existen notables diferencias en el uso de las nuevas tecnologías en diferentes países (¿por qué el éxito del sistema doméstico VTR en Gran Bretaña, o la locura por las galerías de vídeo en los EE.UU.?), y suficientes ejemplos de productos que no se venden pese a las inversiones masivas de capital (desde los sistemas de sonido cuadrafónico a los videodiscos), lo que nos indica que los consumidores no son tan maleables. Al menos en el negocio discográfico, el control oligopolista de los medios de comunicación musicales está permanentemente enfrentado a la preferencia, por parte del consumidor, de aparatos que puedan, en cierto modo, aumentar el control sobre su propio consumo.

En términos musicales, los usos «folk» más interesantes e influyentes de la nueva tecnología han sido desarrollados por músicos negros y audiencias negras, en Jamaica y en los EE.UU. Quizá sea Jamaica el ejemplo más claro de una sociedad en la que la oposición «folk versus tecnología» no tiene sentido. El reggae es una forma folk cuyo centro está ocupado por discos, estudios, músicos de sesión y disc-jockeys, en lugar de actuaciones en vivo o reuniones colectivas. En particular, los disc-jockeys jamaicanos promovieron la utilización de los discos como instrumentos musicales, susceptibles de conversión y de comentario, de aceleración y desaceleración, de cortes transversales y longitudinales, y no como mercancía fija y acabada.

En los años setenta, los disc-jockeys de Nueva York y de otros lugares reflejaron esas ideas (directamente influenciadas por ellas). La consecuencia 
más notable fueron las manifestaciones de bip-hop * en Brooklyn. La cultura del rapping,** la mezcla de sonidos grabados, los graffiti, el break dancing, etc., eran, en términos sociológicos habituales, una cultura de la calle:

«El bip-bop nació de manos de los niños que desarrollaban sus propios entramados sociales, desde las pandillas a los clubs de karate, creando sus propios bailes, su poesía y su música, en un intento de hacer que la ciudad, violenta, cruel, y a menudo incomprensible, se convirtiera en un entorno habitable... En el bip-hop, las corrientes principales de la moda, del arte, del lenguaje, de la cultura del ocio (los valores convencionales) son derrocadas por aquellos que han sido marginados del statu quo» (George y otros, 1985, p. XVII).

Sin embargo, los medios para esta empresa cultural los ha dado la tecnología (el tocadiscos, destructor del ghetto), y todo lo demás, el metro, el cuerpo, el disco, se convirtieron en objetos sobre los que el artista bip-bop podía trabajar. La música bip-bop significaba montaje y collage:

«Telefonear a Tommy Boy Records en febrero de 1984 era todo un reto. Durante el tiempo que te mantuvieran a la espera, escuchabas una legendaria "mezcolanza" que llevaba al bip-bop un paso adelante en su infinito potencial. Utilizando la irresistible base de Play that beat, combinaba fragmentos de Adventures on the Wheels of Steel, algo del poder soul de James Brown, Buffalo Galls, That's the Joint de los Funky Four, West Street Mob, The Supreme Team, Culture Club, Live at the Disco Fever, de Starski, Tutti Frutti, de Little Richard, ejercicios de rutina (punta-tacón, punta-tacón), Humphrey Bogart en Casablanca, Rockit, Stop in the Name of Love, de The Supremes, Planet Rock, Last Night a DJ Saved My Life, de Indeep, y otros» (Toop, 1984, p. 154).

Todos los sonidos podían ser trillados en este molino, tanto charlas políticas, sirenas de policía o conversaciones escuchadas telefónicamente, como efectos accidentales de distorsión electrónica. Como David Toop continúa diciendo:

«La moda coincidente de las grabaciones a trozos y de los teclados de sampling, como el Emulator o el Fairlight, nos han conducido al pillaje

* Hip-bop literalmente significa: contorneo-bailoteo.

** Rapping, son los encuentros que se hacen en la calle, entre los participantes de las diversas actividades, para comentar planes, resultados, etc... (N. del T.) 
creativo a gran escala y ha originado una crisis en los conceptos de propiedad artística de la era precomputadora» (Toop, 1984, p. 154).

Muchos de los mejores discos bip-bop no se pueden adquirir legalmente. La utilización en ellos de «sonidos existentes» representa, para las compañías discográficas, una forma de piratería. El rechazo a aceptar el disco como producto terminado amenaza a la organización base del negocio de la música como empresa rentable. De ahí las virulentas objeciones a la grabación doméstica ( $\mathrm{y}$ el intento sistemático de clasificar a las personas que hacen grabaciones en casa y a los piratas profesionales dentro del mismo grupo). La tecnología electrónica mina la idea de los objetos fijos en los que descansa el derecho de propiedad intelectual, el esencial resguardo legal que tiene el arte como propiedad. De esta manera, el LP de Malcolm McClaren Duck Rock, que es un montaje de sonidos extraídos de la radio de Nueva York y de las calles y núcleos urbanos de Sudáfrica conformado en el estudio de Trevor Horn, necesita un «autor» identificable para poder ser puesto a la venta y para seguir todos los procedimientos en cuanto a sus beneficios.

Aquí es donde radica la ironía final de la relación entre arte y tecnología en el negocio discográfico: los beneficios de las compañías de discos se han de defender de la nueva tecnología en base a la creatividad del individuo. Como demostró John Stratton (1983), el personal de la industria discográfica siempre ha explicado sus actividades, y la «irracional racionalidad» de la música como negocio en los términos ideológicos del Romanticismo. Lo que está ocurriendo ahora es que la tecnología está trastornando el equilibrio implícito entre la «propiedad» del trabajo creativo por parte de los artistas, y la propiedad de la mercancía por parte de las compañías de discos - esta última siempre ha sido defendida basándose en la anterior. El derecho de propiedad intelectual se ha convertido en el arma ideológica y legal con la que atacar a los «piratas». Y, cada vez más, en la fuente de beneficios de las compañías multinacionales, que explotan los derechos de sus producciones dando licencia para su uso a compañías menores y a otros medios de comunicación.

Como señala John Qualen (1985), desde el boom discográfico del rock en los años sesenta, la «crisis» de la industria de la música en los últimos diez años ha ocultado tres cambios significativos en la organización de la obtención de beneficios. En primer lugar, las compañías discográficas $\mathrm{y}$ las editoras son la misma cosa, y la proporción creciente de beneficios viene, de hecho, de la explotación de sus derechos de autor a través de diversas publicaciones, de la Sociedad de Derechos de Autor, etc... En segundo lugar, las compañías más grandes están comercializando cada vez 
más el uso de material de sus archivos con destino a las cadenas independientes de televisión y a los especialistas. En tercer lugar, las compañías de discos han comenzado a amenazar a la radio y a la televisión sobre el uso de discos y vídeos, no para publicidad, para la cual ellos proporcionan material nuevo y barato, sino para todos los programas de animación, que tendrían que pagar precios competitivos por su empleo de las grabaciones:

«En cierta manera, la industria discográfica está enfrentándose con los mismos problemas que la cinematográfica. La base de su mercado está siendo erosionada y fragmentada (las ventas de música grabada han descendido como las de las entradas de los cines), los costes se están disparando, y el sistema tradicional de distribución se está resquebrajando con las nuevas tecnologías.

»Aunque siempre habrá películas taquilleras como ET (o Relax y Emoción), la mayor parte del beneficio de los productores de películas (y de música grabada) vendrán de la explotación de los derechos que tienen sobre sus producciones, de cara a las emisiones de televisión y de televisión por cable. Esta estrategia tiene una doble ventaja en la industria discográfica (que está integrada mucho más verticalmente que la del cine): eliminará, en su mayor parte, los elevados costes de manufacturación y distribución» (Qualen, 1985, p. 16).

\section{CONCLUSION}

Las exigencias políticas de la contracultura de los sesenta solían ser motivo de mofa por su aparente contradicción entre ideología y tecnología. ¿Cómo podía ser que los EE.UU. o Gran Bretaña estuvieran «cubiertos» de amplis Marshall y sistemas de bi-fi de alto precio? Para los enteradillos sobre crítica de cultura de masas, la discusión sobre el progreso tecnológico no tiene mucho fundamento. Basta ver lo que sucedió con Elvis Presley y con el Bob Dylan eléctrico, con el punk y con el bip-bop, en última instancia todos ellos fueron elegidos popularmente. Para la izquierda es un razonamiento familiar, pero descansa en sus propios supuestos dudosos. ¿Puede realmente ser garantizada la verdad musical, cualquiera que sea su verdad de clase, de género, de etnia o de carácter individual, mediante la acústica? Éste es un tema que parece preocupar a los intelectuales del primer mundo, ofuscados quizá por el problema de las raices de su propia cultura, mucho más de lo que preocupa a los demás. Los músicos del tercer mundo, al igual que los músicos de raza negra en los EE.UU., 
rara vez han rechazado adaptar su música a la nueva tecnología (o la nueva tecnología a su música). Compárese con el intenso debate de las feministas americanas sobre la «música de las mujeres». ¿Deberían utilizar las feministas las formas del folk y del jazz, como más «auténticamente» expresivas? ¿O es el punk, el ruido y la estridencia eléctrica la fuente necesaria para una nueva voz?

El debate nos lleva a preguntar, en este punto, a quién quieren llegar los músicos y de qué forma, así como también nos conduce a las ideologías implícitas en las propias formas musicales. Esto significa entrar en el combate existente entre el mercado de la música y el gusto popular, que es la movida de las canciones y los sonidos de la vida diaria. Suponer que lo que sucede a estrellas y movimientos a largo plazo - por elección popular- desacredita el disruptivo impacto a corto plazo, significa confundir la política de la cultura ( $y$ no existe duda en cuanto al desbaratador impacto de Elvis Presley o de los Rolling Stones, de los Sex Pistols o de X-Ray Spex). La tecnología, como posibilidad alternativa a la reproducción mecánica, ha sido, indudablemente, condición necesaria para la expansión del negocio del entretenimiento por las multinacionales y para alcanzar técnicas más sofisticadas de manipulación ideológica, pero también ha hecho posibles nuevas formas de democracia cultural y nuevas posibilidades para la forma de expresión individual y colectiva. No se trata tan sólo de que el «aura» de la cultura tradicional haya sido destruida, sino también de que las máquinas que produce la tecnología han sido las armas más efectivas para músicos y audiencias en su guerra de guerrillas continua en contra del poder cultural del capital y del Estado. Cada nuevo avance en la tecnología de la grabación permite que se escuchen nuevas voces y que lo sean de una manera nueva. $Y$ las voces populares tienen sistemáticamente denegado el acceso a otros medios de comunicación pública. La historia del pop es, en parte, la historia de diferentes grupos utilizando los mismos medios (el disco) para fines diferentes (beneficios, arte, articulación de la comunidad, satisfacción del ego, protesta, etc.). La tecnología determina cómo se organiza la competencia de una voz, pero no quién será escuchado o cómo se interpreta lo que se escucha. Soy de la opinión de que el control capitalista de la música popular no está basado en el control de las compañías discográficas sobre la tecnología de la grabación, sino en su apropiación permanente de la ideología del arte de los músicos y los fans. El hecho de que la ordenación económica de la producción y del consumo de música no haya cambiado todavía, pese a su creciente falta de cohesión con el actual proceso de producción y consumo, refleja el poder de continuidad de las ideas de creatividad y verdad del siglo xIX. 


\section{REFERENCIAS BIBLIOGRAFICAS}

Ala N. et al., 1985: «Patterns of Music Consumption in Milan and Reggio Emilia from April to May 1983», Popular Music Perspective, 2.

Brown M., 1985: «Pop - How Live is Live?», Sunday Times, 17 de Marzo.

Coon C., 1976: 1988: The New Wave Punk Rock Explosion, Londres, Omnibus.

Eckersiy R., 1946: The BBC And All That, Londres, Sampson Low, Marston and Co.

George N., et al., 1985: Fresh, Nueva York, Random House.

Heath T., 1957: Listen To My Music, Londres, Frederick Muller.

Levy A., 1960: Operation Elvis, Londres, André Deutsch.

Qualen J., 1985: The Music Industry, Londres, Comedia.

Rockwell J,, 1984: Sinatra, Nueva York, Random House.

The Rolling Stones, 1964: Our Own Story, Londres, Corgi.

Stratton, J., 1983: «Capitalism and Romantic Ideology in the Record Business», Popular Music, 3.

Toop D., 1984: Tbe Rap Attack, Londres, Pluto Press.

Warner Communications, 1982: Home Taping - A Consumer Survey. 